\title{
Cigarette smoking reduces human gastric luminal prostaglandin $\mathrm{E}_{2}$
}

\author{
D R MCCREADY, L CLARK, AND M M COHEN \\ From the Department of Surgery, University of Toronto, and Mount Sinai Hospital, Toronto, \\ Ontario, Canada
}

SUMmARY The effect of smoking three cigarettes on the release of prostaglandin $\mathrm{E}_{2}\left(\mathrm{PGE}_{2}\right)$ by the gastric mucosa was studied in seven healthy smokers. Smoking caused the expected increases in pulse rate, blood pressure, plasma glucose, and carboxyhaemoglobin. In addition, smoking resulted in a significant $(\mathrm{p}<0.05)$ reduction in the volume of pentagastrin stimulated gastric juice from $76 \cdot 1 \pm 4.4$ to $54 \cdot 1 \pm 4.6 \mathrm{ml} / 15 \mathrm{~min}$ and $\mathrm{PGE}_{2}$ output from $22 \cdot 8 \pm 4.9$ to $12 \cdot 2 \pm 3.8 \mathrm{ng} / 15 \mathrm{~min}$ but did not alter acid output. It is concluded that smoking reduces the amount of $\mathrm{PGE}_{2}$ in the gastric lumen and that this may explain why it is a risk factor for peptic ulcer.

Cigarette smoking is endemic in our society and is a major risk factor for the development ${ }^{1}$ and recurrence $^{2}$ of peptic ulcer. This association cannot be explained on the basis of an effect on gastric secretion of acid or pepsin, ${ }^{3}$ blood flow ${ }^{4}$ or even pancreatic secretion. ${ }^{5}$ It is possible that smoking may adversely affect one or more of the mucosal defence mechanisms. Prostaglandins, particularly $\mathrm{PGE}_{2}$, may play a key role in the maintenance of gastric mucosal integrity. ${ }^{6}$ There is some evidence that smoking may alter prostanoid synthesis. ${ }^{7}$ This study was designed to determine the effect of smoking on gastric mucosal $\mathrm{PGE}_{2}$ in healthy smokers.

\section{Methods}

\section{SUBJECTS}

Seven healthy (weight $76.9 \pm 6.4 \mathrm{~kg}$ ) subjects (five men and two women) aged 21-32 years participated in the study which was approved by the University of Toronto Human Experimentation Committee. All subjects provided informed written consent. None had a significant past medical history nor any symptoms related to the gastrointestinal tract. All were smokers who usually consumed $10-25$ cigarettes per day. No alcohol, aspirin, or other medication were ingested for at least one week before or during the study.

Address for correspondence: Dr M M Cohen, 600 University Avenue, Suite 440. Toronto, Ontario, M5G 1X5, Canada.

Received for publication 4 January 1985
DESIGN OF EXPERIMENT

The subjects were studied twice (smoking and control) at least five and not more than 14 days apart. Each experiment was conducted at the same time of day and the sequence was randomised. In the control experiment a Pasteur pipette was 'smoked'.

Subjects fasted and abstained from smoking for eight hours. A $14 \mathrm{~F}$ gauge double lumen nasogastric tube (Salem Sump, Argyle Co) was passed so that its tip lay in the most dependent portion of the stomach. The gastric contents were aspirated and discarded. Gastric juice was then collected using continuous low pressure suction. Juice was collected in 15 minute aliquots in a specimen flask (Cheeseborough Ponds Inc) placed in an ice-water bath. Saliva was expectorated.

Throughout every experiment pentagastrin $6 \mu \mathrm{g} /$ $\mathrm{kg} / \mathrm{h}$ was given in normal saline by continuous intravenous infusion to obtain maximal gastric secretion. A catheter was placed intravenously in the opposite arm for blood sampling. A plateau of secretion was reached within 15 minutes. The first 15 minute aliquot was discarded. The next 45 minutes was designated as the 'baseline' period, after which the subjects smoked three cigarettes (DuMaurier King-Size Filter tipped), each of which contained $1.2 \mathrm{mg}$ nicotine and $16 \mathrm{mg}$ 'tar', at the rate of one cigarette per 10 minutes. They were instructed to inhale the cigarette for two seconds, hold the smoke for three seconds, exhale, and then repeat the sequence every 30 seconds. The cigarette was smoked until reduced to a length of $2.5 \mathrm{~cm}$. 
Gastric juice from the 'smoking' period consisted of the two aliquots during actual smoking plus the next 15 minute aliquot. Gastric secretion was collected for a further 45 minutes defined as the 'postsmoking' period. Blood was drawn from the intravenous catheter $0,60,75,90,120$, and 150 minutes after the pentagastrin infusion was started. Blood pressure and heart rate were recorded every 15 minutes.

\section{MEASUREMENTS}

The volume of each aliquot was measured and its $\mathrm{H}^{+}$concentration determined by titration to $\mathrm{pH} 7 \cdot 0$ with $0.01 \mathrm{M} \mathrm{NaOH}$ using an automatic titrimeter (Radiometer, Copenhagen). $\mathrm{PGE}_{2}$ concentration was measured by radioimmunoassay after extraction and column chromatography as previously described. ${ }^{8}$ Briefly, a $1 \mathrm{ml}$ aliquot of gastric juice was titrated with $1 \mathrm{M} \mathrm{NaOH}$ solution to a $\mathrm{pH}$ between $3 \cdot 0$ and 3.5. Tritiated $\mathrm{PGE}_{2}$ was added to determine recovery. It was extracted twice with $4 \mathrm{ml}$ ethyl acetate, dried at $37^{\circ} \mathrm{C}$ under a stream of nitrogen, and stored at $-70^{\circ} \mathrm{C}$ until silicic acid chromatography and radioimmunoassay. The radioimmunoassay utilised antibody from the Pasteur Institute and achieved $50 \%$ binding at $9 \cdot 1 \pm 0 \cdot 3 \mathrm{pgPGE}_{2}$ per assay tube. Tritiated $\mathrm{PGE}_{2}$ was obtained from New England Nuclear. $\mathrm{PGE}_{2}$ for the standards was a generous gift from Dr John Pike, Upjohn, Kalamazoo. Interassay and intraassay coeficients of variation were consistently less than $10 \%$. Plasma glucose concentrations were determined by the oxidase method $^{9}$ using the Beckman Glucose Analyser II. Blood for carboxyhaemoglobin was drawn into heparinised syringes, kept on ice, and analysed by co-oximeter (Model 282, Instrumentation Laboratory).

\section{ANALYSIS OF DATA}

A two way analysis of variance was used to determine statistical significance. If the initial analysis on the raw data proved significant, further analysis was carried out by transforming the data into 'percentage of baseline'. Student's $t$ test was then used to determine the significance of the difference between baseline and subsequent measurements. A p value of less than 0.05 was considered significant. In this way the analysis helped factor out differences between individuals. The results are reported conventionally as mean \pm standard error of actual values.

\section{Results}

Cigarette smoking had a significant effect on gastric secretion (Fig. 1). The volume of juice was significantly reduced from $76 \cdot 1 \pm 4 \cdot 4$ to $54 \cdot 1 \pm 4 \cdot 6 \mathrm{ml} / 15$
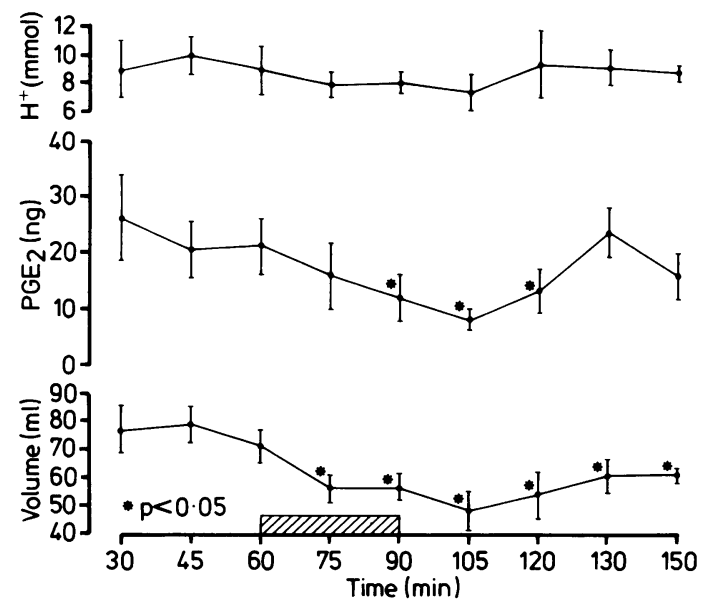

Fig. 1 Gastric secretion stimulated by pentagastrin in healthy adults. Each point represents the mean $15 \mathrm{~min}$ output for seven subjects. The bars represent $S E$ of the means. Subjects smoked three cigarettes during the interval represented by the shaded bar. The asterisks indicate values significantly different from the mean of the first three values (baseline perio'd).

minutes in the smoking period, an average reduction of $29 \%$. In the postsmoking period the volume recovered slightly. $\mathrm{PGE}_{2}$ output was also significantly reduced by an average of $46 \%$. The baseline value of $22 \cdot 8 \pm 4.9 \mathrm{ng} / 15$ minutes dropped to $12 \cdot 2 \pm 3 \cdot 8$ ng/15 minutes during the smoking period and increased to $17.9 \pm 3.0 \mathrm{ng} / 15$ minutes in the postsmoking period. Acid output fell slightly during the smoking period but this was not statistically significant.

Cigarette smoking caused a significant rise in the pulse, and blood pressure (Fig. 2). Plasma glucose was significantly increased from $4.93 \pm 0.07$ to $5 \cdot 12 \pm 0 \cdot 06$ in the smoking period and $5 \cdot 31 \pm 0 \cdot 10$ $\mathrm{mmol} / \mathrm{l}$ in the postsmoking period. Carboxyhaemoglobin increased significantly from $0.45 \pm 0 \cdot 10$ to $0 \cdot 61 \pm 0.13$ and $0.59 \pm 0.11$ in the smoking and postsmoking periods respectively. The results obtained during the smoking of sham cigarettes are shown in the Table. No significant changes were found nor were there any changes in pulse rate, or blood pressure (Fig. 2).

A comparison of the data obtained during the sham-smoking experiment was made with the data from the smoking experiment using analysis of variance. Smoking caused a significant $(\mathrm{p}<0.05)$ reduction in $\mathrm{PGE}_{2}$ output $(12.2 \pm 3.8 \mathrm{ng} / 15$ minutes) and of volume of secretion $(54.1 \pm 4.6 \mathrm{ml} / 15 \mathrm{mi}-$ nutes) during the smoking period but there was no 


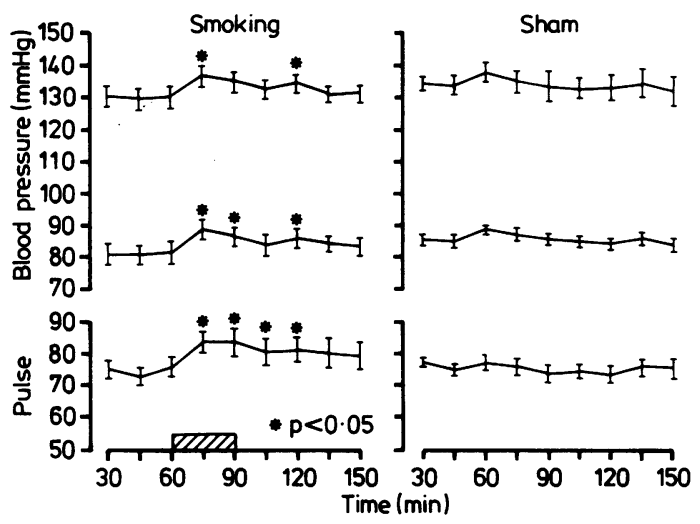

Fig. 2 Heart rate and blood pressure values obtained in the smoking and control experiments. Each point represents the mean value for seven subjects. The bars represent $S E$ of the means. Subjects smoked three cigarettes during the interval represented by the shaded bar. The asterisks indicate values significantly different from the mean of the first three values (baseline period).

significant change in acid output $(7 \cdot 9 \pm 0 \cdot 7 \mathrm{mEq} / 15$ minutes).

\section{Discussion}

The circumstantial evidence that cigarette smoking has an adverse effect on the gastroduodenal mucosa is considerable. There is not only an epidemiological association between smoking and peptic ulceration ${ }^{1}$ but also evidence that stopping smoking promotes ulcer healing. ${ }^{10}$ It has been generally assumed that smoking is not a direct cause of ulceration but rather a factor preventing the healing of mucosal lesions indirectly via either a secretory effect or an effect on gastric mucosal defence.

The mechanism(s) underlying the harmful effects of cigarette smoking on peptic ulcer are not understood. The effect of smoking on gastric secretion of acid and pepsin is reported to be either inhibitory or nil. ${ }^{311-15}$ There is some evidence that cigarette smoking decreases gastric ${ }^{5}$ and pancreatic bicarbon-

Table Results obtained in the control experiment

\begin{tabular}{|c|c|c|c|}
\hline & Baseline & $\begin{array}{l}\text { Sham- } \\
\text { smoking }\end{array}$ & $\begin{array}{l}\text { Post- } \\
\text { smoking }\end{array}$ \\
\hline $\begin{array}{l}\mathrm{PGE}_{2}(\mathrm{ng} / 15 \mathrm{Min}) \\
\mathrm{Vol}(\mathrm{ml} / 15 \mathrm{~min}) \\
\mathrm{H}^{+}(\mathrm{mmol} / 15 \mathrm{~min}) \\
\text { Glucose }(\mathrm{mmol} / \mathrm{)}) \\
\text { Co } \mathrm{Hb}\end{array}$ & $\begin{array}{c}19 \cdot 2 \pm 5 \cdot 9 \\
75 \cdot 6 \pm 6 \cdot 2 \\
9 \cdot 0+1 \cdot 1 \\
4 \cdot 96+0 \cdot 09 \\
0 \cdot 41 \pm 0 \cdot 07\end{array}$ & $\begin{array}{c}24 \cdot 5 \pm 7 \cdot 4 \\
68 \cdot 7 \pm 3 \cdot 3 \\
9 \cdot 4 \pm 1 \cdot 0 \\
4 \cdot 96 \pm 0 \cdot 07 \\
0 \cdot 41 \pm 0 \cdot 06\end{array}$ & $\begin{array}{c}23 \cdot 4 \pm 7 \cdot 8 \\
64 \cdot 2 \pm 5 \cdot 3 \\
9 \cdot 2 \pm 1 \cdot 1 \\
5 \cdot 14 \pm 0 \cdot 12 \\
0 \cdot 40 \pm 0 \cdot 06\end{array}$ \\
\hline
\end{tabular}

ate output. 51617 This could in part explain the adverse effect of smoking on duodenal and gastric ulcer. There is conflicting data on the effect of smoking on gastric mucus secretion. ${ }^{18} 19$ The other factors putatively involved in mucosal defence such as cell turnover and mucosal blood flow have either not been studied or have been shown not to be altered. $^{4}$

It has been suggested that endogenous gastric mucosal prostaglandins may play an important role in the maintenance of mucosal integrity. ${ }^{20}$ There is now a large volume of data showing that exogenous prostaglandins are capable of preventing mucosal damage in animals and in man. ${ }^{21}$ There is evidence that endogenous prostaglandin synthesis can be induced by 'mild irritants' ${ }^{22} 23$ and by stress. ${ }^{24}$ The prostaglandin content of gastric mucosa may be decreased in patients with gastric ulceration or gastric cancer. ${ }^{25}$ Duodenal ulcer patients may have impaired prostaglandin release by their duodenal mucosa in response to an acid and food load. ${ }^{26}$ Further, drugs which inhibit gastric mucosal prostaglandin synthesis, for example aspirin and indomethacin, typically injure the gastric mucosa.

Smoking has been shown to alter prostaglandin metabolism in other organ systems. For example, aspirin (a cyclooxygenase inhibitor) prevented the smoking induced platelet aggregate formation in non-smokers. ${ }^{27}$ Cigarette smoke reduced prostacyclin production by rat aorta in vitro. ${ }^{28}$ The neonates of women who smoked throughout pregnancy had decreased umbilical artery prostacyclin synthesis immediately after delivery.$^{29}$ It was therefore reasonable to explore the possibility that smoking mmight impair prostaglandin production by the human gastric mucosa.

This study shows that the smoking of three cigarettes over 30 minutes by healthy adult smokers causes a significant reduction in the total volume of gastric juice but not of acid output. This suggests that smoking inhibits non-parietal cell secretion and is consistent with other reports. ${ }^{45}$ This could be an autonomic effect mediated by changes in blood flow. Smoking also caused a significant reduction in the amount of $\mathrm{PGE}_{2}$ found in the gastric lumen. That smoking reduced luminal $\mathrm{PGE}_{2}$ in habitual smokers makes our finding even more striking as non-smokers might be expected to be more sensitive to the effects of smoking. Fung $e^{2} a^{30}$ found no change in the concentration of 6-keto prostaglandin $F_{1 \alpha}$ (the stable metabolite of prostacyclin) in the gastric juice of volunteers who smoked three cigarettes over a one hour period. In that study there was enormous variation in the 6-keto PGF $_{1 \alpha}$ values in the basal collections and throughout the control experiment. This would have concealed all 
but the most profound inhibition of prostacyclin release. We chose to study $\mathrm{PGE}_{2}$ because it is the predominant prostanoid found in human gastric juice $^{31}$ and we used a background of maximal gastric secretion in an attempt to stabilise $\mathrm{PGE}_{2}$ output. This was successful as demonstrated by the remarkably stable $\mathrm{PGE}_{2}$ concentrations in the shamsmoking experiment.

The precise mechanism by which $\mathrm{PGE}_{2}$ appears in the gastric juice is not known. We do not know whether smoking inhibited the cyclooxygenase system, inhibited the active secretion of $\mathrm{PGE}_{2}$, reduced passive transport of $\mathrm{PGE}_{2}$ into the lumen, or enhanced $\mathrm{PGE}_{2}$ degradation. The lack of effect on gastric acid output and the stability of the luminal $\mathrm{pH}$, makes the latter explanation less likely. Whatever the mechanism, the end result was that smoking reduced the absolute amount of $\mathrm{PGE}_{2}$ in contact with the surface mucosal cells. Admittedly the amount of $\mathrm{PGE}_{2}$ detected by us in the gastric juice was very small and substantially smaller than the smallest amount of exogenous $\mathrm{PGE}_{2}(40 \mu \mathrm{g})$ found by us to protect against aspirin injury. ${ }^{32}$ If, however, as seems likely, endogenous $\mathrm{PGE}_{2}$ plays a role in the complex regulation of mucosal integrity ${ }^{6}$ then an approximately $50 \%$ reduction in luminal $\mathrm{PGE}_{2}$ may be sufficient to impair resistance to injury, facilitate the development of ulceration, and prevent the healing of an ulcer once formed. Measurement of $\mathrm{PGE}_{2}$ in the gastric juice may not be the optimum way of examining this problem. It may be preferable to examine the prostaglandin synthetic capacity of mucosal biopsies. ${ }^{8}$ We are now conducting endoscopic studies in normal subjects and patients with peptic ulcer to explore the effect of smoking on the major prostanoids of the gastric mucosa.

We thank $\mathbf{R}$ Bowdler for his expert technical assistance, the nursing staff of the Gastrointestinal Unit, Mount Sinai Hospital for their cooperation, and Miss Helen Gigas for secretarial assistance. This work was supported by the Medical Research Council of Canada, Grant No MT5316 and by the Mount Sinai Institute.

This work was presented at the 70th Annual Clinical Congress of the American College of Surgeons, San Francisco, October 23rd, 1984, and an abstract published (Surgical Forum 1984; 35: 200).

\section{References}

1 Friedman GD, Seiglaub AB, Seltzer CC. Cigarettes, alcohol, coffee and peptic ulcer. N Engl J Med 1974; 290: 469-73.
2 Sonnenberg A, Muller-Lissner SA, Vogel E et al. Predictors of duodenal ulcer healing and relapse. Gastroenterology 1981; 81: 1061-7.

3 Debas HT, Cohen MM, Holubitsky IB, Harrison RC. Effect of cigarette smoking on gastric secretory responses. Gut 1971; 12: 93-6.

4 Sonnenberg A, Husmert N. Effect of nicotine on gastric mucosal blood flow and acid secretion. Gut 1982; 23: 532-5.

5 Murthy SNS, Dinoso VP, Clearfield HR, Chey WY. Simultaneous measurement of basal pancreatic, gastric acid secretion, plasma gastrin, and secretin during smoking. Gastroenterology 1977; 73: 758-61.

6 Miller TA. Protective effects of prostaglandins against gastric mucosal damage: current knowledge and proposed mechanisms. Am J Physiol 1983; 245: G601-23.

7 Mehta P, Mehta J. Effects of smoking on platelets and on plasma prostacyclin-thromboxane balance in men. Prostaglandins Leuk Med 1982; 9: 141-50.

8 McCready DR, Wallace JL, Cohen MM. Prostaglandin biosynthesis by gastric mucosa. II. Studies in man. Clin Biochem 1984; 17: 183-7.

9 Kadish AH, Litle RL, Sternberg JC. A new and rapid method for the determination of glucose by the measurement of rate of oxygen consumption. Clin Chem 1975; 14: 116-31.

10 Doll R, Jones FA, Pygott F. Effect of smoking on the production and maintenance of gastric and duodenal ulcers. Lancet 1958; 1: 657-62.

11 Schnedorf JG, Ivy AC. The effect of smoking tobacco on the alimentary tract. An experiment of man and animal. JAMA 1939; 112: 898-904.

12 Steigman F, Dolehide RH, Kaminski L. Effect of tobacco smoking on gastric acidity and motility in hospital controls and patients with peptic ulcer. Am J Gastroenterol 1954; 22: 399-409.

13 Cooper P, Knight JB. Effect of cigarette smoking on gastric secretion of patients with duodenal ulcer. $N$ Engl J Med 1956; 255: 17-21.

14 Fung WP, Tye CY. Effect of smoking on gastric acid secretion. Aust NZ J Med 1973; 3: 251-4.

15 Wilkinson AR, Johnston D. Inhibitory effect of cigarette smoking on gastric secretion stimulated by pentagastrin in man. Lancet 1971; 2: 628-32.

16 Bochenek WJ, Koronczewski R. Effect of cigarette smoking on bicarbonate and volume of duodenal contents. Am J Dig Dis 1973; 18: 729-33.

17 Bynum TE, Solomon TE, Johnson LR, Jacobson ED. Inhibition of pancreatic function in man by cigarette smoking. Gut 1972; 13: 361-5.

18 Cooper P, Saltz M, Harrower HW, Burke DH. Effect of cigarette smoking on dissolved gastric mucins and viscosity of gastric juice. Gastroenterology 1957; 33: 959-67.

19 Yeomans ND, Millar SJ. Effect of tobacco-smoke condensate on mucus, protein and DNA synthesis in cultured antral mucosa. Aust NZ J Med 1980; 10: 590.

20 Cohen MM. Prostaglandin therapy for gastric ulcer. Lancet 1977; 1: 308.

21 Cohen MM. Gastric mucosal protection with prostaglandins. In: Pfeiffer CJ, ed. Drugs and peptic ulcer. Vol. I. Boca Raton, Florida: CRC Press, 1982: 133-46. 
22 Robert A, Nezamis JE, Lancaster C, Davis JP, Field SO, Hanchar AJ. Mild irritants prevent gastric necrosis through 'adaptive cytoprotection' mediated by prostaglandins. Am J Physiol 1983; 245: G113-21.

23 Cohen MM. Diflunisal protects human gastric mucosa against damage by indomethacin. Dig Dis Sci 1983; 28: 1070-7.

24 Wallace JL, Cohen MM. Gastric mucosal protection with chronic mild restraint: role of endogenous prostaglandins. Am J Physiol 1984; 247: G127-32.

25 Wright JP, Young GO, Klaff LJ, Weers LA, Price SK, Marks IN. Gastric mucosal prostaglandin $E_{2}$ levels in patients with gastric ulcer disease and carcinoma. Gastroenterology 1982; 82: 263-7.

26 Ahlquist DA, Dozois RR, Zinsmeister AR, Malagelada J-R. Duodenal prostaglandin synthesis and acid load in health and in duodenal ulcer disease. Gastroenterology 1983; 85: 522-8.

27 Davis JW, Davis RF. Prevention of cigarette smoking- induced platelet aggregate formation by aspirin. Arch Intern Med 1981; 141: 206-7.

28 Pittilo RM, Mackie IJ, Rowles PM, Machin SJ, Woolf N. Effects of cigarette smoking. on the ultrastructure of rat thoracic aorta and its ability to produce prostacyclin. Thromb Haemostas 1982; 48: 173-6.

29 Dadak CH, Leithner $\mathrm{CH}$, Sinzinger H, Silberbauer $\mathrm{K}$. Diminished prostacyclin formation in umbilical arteries of babies born to women who smoke. Lancet 1981; 1: 94.

30 Fung WP, Mahoney DP, Beilin LJ. Effect of cigarette smoking on gastric secretion of 6-keto prostaglandin $\mathrm{F}_{1 \alpha}$. Aust NZ J Med 1982; 12: 206-10.

31 Peskar BM, Gunter B, Peskar BA. Prostaglandins and prostaglandin metabolites in human gastric juice. Prostaglandins 1980; 20: 419-27.

32 Cohen MM. Prevention of aspirin-induced fecal blood loss with oral prostaglandin $\mathrm{E}_{2}$ : dose-response studies in man. Prostaglandins 1981; suppl 21: 155-60. 